\title{
Abordagem Prática de Bioinformática em Evento Acadêmico-Científico na Cidade de Fortaleza-Ce
}

\author{
Howard Lopes Ribeiro Junior \\ Roberta Taiane Germano de Oliveira \\ Alex Soares Marreiros Ferraz \\ Francisco Fleury Uchoa Santos Júnior \\ Patrick Simão Carlos \\ André Accioly Nogueira Machado \\ Igor Cabral Coutinho do Rêgo Monteiro \\ Vânia Marilande Ceccatto
}

\begin{abstract}
Resumo
O objetivo deste estudo foi aplicar e avaliar conteúdos teóricos-práticos de Bioinformática para estudantes participantes do Curso Introdução à Bioinformática: Da Teoria à Prática, inserido na programação da IX Semana da Biologia na Universidade Estadual do Ceará, no ano de 2010. A abordagem teórica consistiu de uma apresentação de conceitos históricos, básicos e específicos dos atuais avanços das pesquisas envolvidas as áreas da biologia Molecular. A prática de "Construção de uma Filogenia Molecular in Silico" foi elaborada para tornar funcional os conceitos apresentados na prática anterior, com a utilização do banco de dados do National Center for Biotechnology Information, NCBI, e sua ferramenta de alinhamento de sequências, o BLASTp (Basic Local Alignment Search Tool Protein-Protein.) Os resultados positivos obtidos com a aplicação da aula teórica de Introdução à Bioinformática e das atividades práticas foram destacados com as caracterizações das filogenias moleculares das sequências hipotéticas propostas para a execução dos alinhamentos e pelas falas dos alunos anteriormente citados. Estas atividades foram vistas como essenciais para que os alunos pudessem vivenciar o passo a passo para uma melhor compreensão da emergente área das ciências da vida: a Bioinformática.
\end{abstract}

Palavras-chave: Bioinformática, Práticas de Ensino, Evento Científico.

\section{Abstract}


Practical Bioinformatics Approach in Academic and Scientific Event in the City of Fortaleza - CE

The aim of this study was to evaluate and apply theoretical concepts and practical for the Bioinformatics student participants of the course Introduction to Bioinformatics: From Theory to Practice, inserted into the programming of ninth week of biology at the State University of Ceará, in 2010. The theoretical approach consisted of a presentation of historical concepts, basic and type of current advances in research involved the areas of Molecular Biology. The practice of "Building a Molecular Phylogeny in Silico" is designed to become functional in practice the concepts presented above, using the database of the National Center for Biotechnology Information, NCBI, and their sequence alignment tool, the blastp (Basic Local Alignment Search Tool Protein-Protein.) Positive results obtained with the application of the lecture "Introduction to Bioinformatics and practical activities were highlighted with the characterizations of the molecular phylogeny of the sequences hypothetical proposals for the implementation of the alignments and the speeches of students mentioned above. These activities were seen as essential so that students could experience step by step to a better understanding of the emerging field of life science: bioinformatics.

Keywords: Bioinformatics, Practice Teaching, Scientific Event.

\section{Introdução}

Vivemos uma época de grandes conquistas nos variados campos das Ciências Biológicas. Neste século, verifica-se a emergência da era genômica e pós-genômica, que se destaca a Bioinformática como uma ferramenta emergente e essencial. A partir destas ferramentas disponíveis online é possível obter, armazenar, classificar e interpretar os volumosos dados gerados por sequenciamento do DNA e proteínas, caracterizando as ômicas, como a genômica e proteômica.

A estrutura do DNA, determinada, no início dos anos 1950, iniciou uma revolução em termos científicos. Logo iniciou-se um corrida para mapear e interpretar o DNA a fim de buscar soluções para a cura de doenças ou simplesmente entender melhor os processos fisiológicos dos seres vivos (Lehninger, 2000).

Com o advento dos supercomputadores e a grande massa de dados advindos dos projetos de sequenciamento de DNA e proteínas, surgiu a necessidade de desenvolvimento de um sistema de computação que armazenasse e analisasse as enormes quantidades de dados gerados por esse projeto; a este sistema deu-se o nome de Bioinformática (Perezelo, 2003). Com a popularização 
da rede mundial de computadores, estes dados tornaram-se disponíveis aos pesquisadores, educadores e estudantes.

A princípio, pode-se relevar o potencial da bioinformática, caracterizando-a essencialmente como ferramenta para a grande massa de pesquisadores nas áreas biomédicas. Em termos curriculares, vários cursos, nas regiões mais desenvolvidas para o ramo da Bioinformática no Brasil, já incorporaram a cadeira de bioinformática nos currículos das graduações de biologia e em outras áreas de saúde, especialmente nas graduações de biomedicina, química, biotecnologia e afins.

\section{Fundamentação Teórica}

O desconhecimento na área da Bioinformática, nos estados nordestinos, é tão grande, que o assunto só é tratado raríssimas vezes em cursos de mestrado e doutorado, mesmo assim, em curtos seminários e palestras de professores visitantes. Este desconhecimento têm gerado distanciamento da área e assim, é possível um prejuízo a curto e médio prazo de nossos profissionais Biólogos e afins.

Uma solução simplista para resolver o problema da Biologia Molecular, seria um incentivo maior sobre os cursos de atualização, tal como a IX Semana da Biologia, apresentada neste estudo, nos quais especialistas seriam contratados para a "transmissão" de conhecimentos novos e a "organização" da confusa rede conceitual (Camargo, 2007).

A disseminação do uso de ferramentas online pelos alunos e professores de Biologia, em sala de aula, é inegável. Blogs, emails, sites, chats e redes sociais são amplamente utilizadas pelos alunos e professores como recurso didático. Vivencia-se no estado do Ceará a experiência de cursos à distância em biologia, o que prenuncia a disseminação de uso de plataformas e softwares online que possibilitam uma nova experiência para o educando.

A Bioinformática, pelo seu caráter bivalente, possibilitaria então uma iniciativa natural para pôr em prática novos paradigmas de ensino. Então, seria possível os atuais alunos dos cursos de Ciências da Vida aproveitar-se das ferramentas de Bioinformática como ferramenta de aprendizagem nos estudos dos conteúdos de Biologia Molecular, Celular e Genética? Este potencial de uso poderia então ser um dos elementos transformadores para a inserção de novas tecnologias, inovação e boas práticas pedagógicas que poderiam ser de grande alcance para o biólogo pesquisador e educador.

A Legislação Brasileira trata deste assunto quando prevê nos PCNEM - Parâmetros Curriculares Nacionais do Ensino Médio - uma reorganização curricular em três grandes áreas (Linguagem, Códigos e suas Tecnologias; Ciências da Natureza, Matemática e suas Tecnologias; Ciências Humanas e suas Tecnologias) que se interligam através de um conjunto de eixos de competências e habilidades (Representação e Comunicação; Investigação e Compreensão; 
Contextualização Sócio-Cultural), pressupondo um processo de ensino capaz de permitir ao estudante a construção de competências cognitivas e sócio-afetivas que qualifiquem o egresso do ensino médio como um sujeito crítico, capaz de solucionar problemas e tomar decisões frente aos desafios da sociedade contemporânea (Brasil, 1999).

A Lei de Diretrizes e Bases para a Educação Brasileira (LDB), as Diretrizes e os Parâmetros Curriculares Nacionais para o Ensino Médio (PCNEM) e as Orientações Educacionais Complementares aos Parâmetros Curriculares Nacionais ( $\mathrm{PCN}+$ ) deram a este nível de escolaridade uma nova perspectiva e atribuições para a educação de jovens e adultos. Dessa forma, pressupõem que o ensino médio deva capacitar o estudante, que venha concluí-lo, para "tomar decisões ao longo de sua vida e intervir socialmente" (Brasil, 1999).

Este tipo de aprendizagem por competências requer, na prática, a construção coletiva de um currículo flexível e que tenha como pilares a contextualização dos conteúdos e a interdisciplinaridade como princípios da ação pedagógica. Ricardo (2003) Aponta para o distanciamento entre o que está proposto nas mais recentes políticas educativas e a prática escolar, cuja superação tem-se mostrado difícil por diversos fatores, dentre eles, a incompreensão dos fundamentos da LDB, das Diretrizes e dos PCNEM por aqueles que são responsáveis pela concretização do projeto político-pedagógico da escola e, conseqüentemente, do currículo.

Quanto à temática proposta, não é raro observar que o genoma, por exemplo, seja tratado em sala de aula de forma etérea, marginal e deslocado dos objetivos das disciplinas de Biologia Molecular e Genética. O conhecimento genômico é concreto, está disponível e pode ser alcançado e trabalhado pelos estudantes, independentemente da área em que se especializarem. Por exemplo, os alunos interessados em botânica ou zoologia, podem se questionar sobre quais as espécies vegetais e animais que possuem o seu genoma já sequenciado? Quantos genes foram listados nestes genomas e, destes, quantos e quais os genes estão ligados à produção de hormônios? Qual o tamanho destes genomas e como estas informações se correlacionam em termos da questão evolutiva?

A partir dos pontos apresentados, este trabalho buscou apresentar a execução do curso de "Introdução à Bioinformática: da Teoria à Prática" realizado na IX Semana da Biologia na Universidade Estadual do Ceará. Este curso teve por objetivo apresentar a temática de Bioinformática de uma forma bastante inicial, capturando a idéia das ferramentas utilizadas para as mais diversas análises dos Genomas em sala de aula, já que ele permeia em todos os conteúdos de Biologia Molecular e Genética, porém não se concretiza, em muitos casos.

Neste trabalho, propõe-se que o estudante possa ter um primeiro contato com a disciplina de Bioinformática através da aplicação de questionamentos, aula expositiva, práticas manual e 
prática in silico. Com isto, este trabalho buscou observar a reação de alunos participantes do curso em questão quando apresentados à ferramentas simples de Bioinformática, produtoras de filogenias moleculares.

\section{Procedimentos Metodológicos}

A realização desta pesquisa foi aprovada pelo Comitê de Ética em Pesquisa com Seres Humanos da Universidade Estadual do Ceará através do processo $N^{\circ} 10244841-8$. A fonte direta de dados foram os 25 (vinte e cinco) alunos que realizaram a IX Semana da Biologia, no período 27 de Setembro à 01 de Outubro de 2010, na Universidade Estadual do Ceará, de no Campus do Itaperi, Fortaleza, Ceará. Foram excluídos da pesquisa os alunos que não assinaram o Termo de Consentimento Livre e Esclarecido e/ou não se comprometeram a execução das atividades pertinentes ao desenvolvimento deste estudo.

Os instrumentos de pesquisa a serem utilizados consistiram de uma aula expositiva e duas atividades práticas, sendo aplicadas logo após a aula teórica de "Introdução à Bioinformática". No início ( $1^{\circ}$ dia) das atividades do "Curso de Introdução à Bioinformática: Da teoria à Prática" foram abordados os temas básicos de Biologia Molecular, tais como Ácidos Nucléicos, Tecnologia do DNA Recombinante (PCR, Sequenciamento, Eletroforeses) e metodologias de análises moleculares.

No 2ำ dia de curso, foi aplicada a aula teórica de Introdução à Bioinformática: Da Teoria à Prática, onde foram abordados os seguintes temas: Breve Histórico da Biologia Molecular, Tecnologia do DNA Recombinante, Projeto Genoma Humano, Introdução ao Alinhamento Múltiplo de Sequências de Nucleotídeos, Construção de uma Matriz de Substituição e Ferramentas de Análises para Construção de uma Filogenia Molecular.

Após este momento, foram apresentadas aos alunos as atividades práticas a serem executadas em sala de aula, assim apresentadas:

1) Construção de uma Filogenia Molecular Manual;

2) Construção de uma Filogenia Molecular in silico.

A atividade "Construção de uma Filogenia Molecular Manual" consistiu de dois passos:

10 - No primeiro passo, foram distribuidos 5 sequências hipotéticas. Neste momento, o aluno devería realizar um alinhamento das sequências a partir dos scores apresentados (Tabela 01), como também indicando as posições altamente conservadas ou não. 
Tabela 1 - Descrição das Alterações a serem Observadas na Execução das

Atividades de Alinhamento de Sequências

\begin{tabular}{ccc} 
Alterações & Scores & Motivos \\
\hline Posição Variável & 1 & $\begin{array}{c}\text { Transversão } \\
\text { Purinas } \rightarrow \text { Pirimidinas ou o } \\
\text { contrário }\end{array}$ \\
\hline Posição Conservada & 2 & $\begin{array}{c}\text { Transição } \\
\text { Pirimidinas } \rightarrow \text { Pirimidina ou } \\
\text { purina } \rightarrow \text { Purina }\end{array}$ \\
\hline Posição Altamente Conservada & 3 & $\begin{array}{c}\text { Mantém o mesmo } \\
\text { Nucleotídeo }\end{array}$ \\
\hline Posição com deleção & -1 & Perca do Nucleotídeo \\
\hline
\end{tabular}

2o - No segundo passo, foi solicitado ao aluno que ele realizasse uma comparação duas a duas entre as sequências e inserisse seus valores de score em uma Matriz de Substituição. Após a construção da Matriz, os alunos foram orientados a construírem as árvores filogenéticas das comparações entre as sequências alinhadas anteriormente.

A atividade de "Construção de uma Filogenia Molecular in silico" foi desenvolvida no Laboratório de Informática da Secretaria de Educação a Distância no Campus do Itaperi - UECE. Esta atividade consistiu da utilização da Ferramenta de alinhamento de sequências BLASTp (Basic Local Alignment Search Tool Protein-Protein) do NCBI (National Center for Biotechnology Information) para o alinhamento de uma sequência de aminoácidos com as já existentes neste banco de dados.

Após o alinhamento, foram apresentados os principais dados observáveis deste tipo de análise bioinformática, em especial, a ferramenta "Distance Tree of Results" que apresenta a comparação filogenética da sequência plotada com outras já existentes.

Ao fim das atividades práticas, os alunos descreveram, sob a forma de um pequeno texto, quais foram os pontos positivos e negativos obtidos com a execução destas aulas práticas.

\section{Análises e Discussões dos Resultados}

As aplicações das aulas práticas foram iniciadas com a execução da aula teórica intitulada de "Introdução à Bioinformática: Teórico - Prático", ministrada pelo autor desta pesquisa, em sala de aula, na Universidade Estadual do Ceará. 
Nesta aula teórica foram abordados tópicos relacionados ao histórico nos conceitos relacionados à Biologia Molecular, o Fluxo da Informação Genética,, o desenvolvimento do Projeto Genoma Humano, a construção dos bancos de dados de sequências e, por fim, o advento da Bioinformática no mundo contemporâneo.

O objetivo da aplicação desta apresentação prática foi fazer uma pequena introdução teórica em relação ao que seria visto diretamente no portal do NCBI, e posteriormente, na aplicação das atividades práticas propostas neste estudo.

\section{Execução das Atividades Práticas "Construção de uma Filogenia Molecular Manual e in Silico"}

Após a aula expositiva foi aplicada a atividade prática intitulada "Construção de uma Filogenia Molecular Manual". Neste momento, foram abordados os estudos de alinhamento de sequências como também suas utilizações, metodologias e mecanismos de análises, tendo como foco permitir por parte dos alunos o desenvolvimento de uma matriz de substituição com os "scores" obtidos do alinhamento e, por conclusão, desenharem uma filogenia molecular que representasse a aproximação evolutiva entre as sequências fornecidas na atividade.

Para um alinhamento coerente, o aluno deve possuir o conhecimento a cerca dos diferentes tipos de mutações e substituições de nucleotídeos. Mutações ocorrem ao acaso em qualquer parte do genoma e podem ser transições, transversões, deleções/inserções e inversões. Substituições referem-se a regiões codificantes e podem ser sinônimas (quando não há alteração do aminoácido codificado), não sinônimas (quando há alteração) e sem sentido (quando um códon de parada é gerado).

Em todas as metodologias de filogenética molecular, cada posição ocupada na seqüência (nucleotídeo ou aminoácido) é considerada como um caráter do tipo multi-estado (podendo ser um dos quatro nucleotídeos ou um dos vinte aminoácidos) e cada caráter é considerado independente dos demais. A variação dos estados de caracteres fornecerá informações filogenéticas (Meneghello, 2004).

A Figura 01 mostra que a temática central sobre alinhamento múltiplo de sequências de nucleotídeos e a posterior construção das árvores filogenéticas elaboradas pelos alunos foi aplicada e compreendida com sucesso, podendo ser observado que os alunos se esforçaram a entender o princípio fundamental da lógica de alinhamento parcial de sequências. 

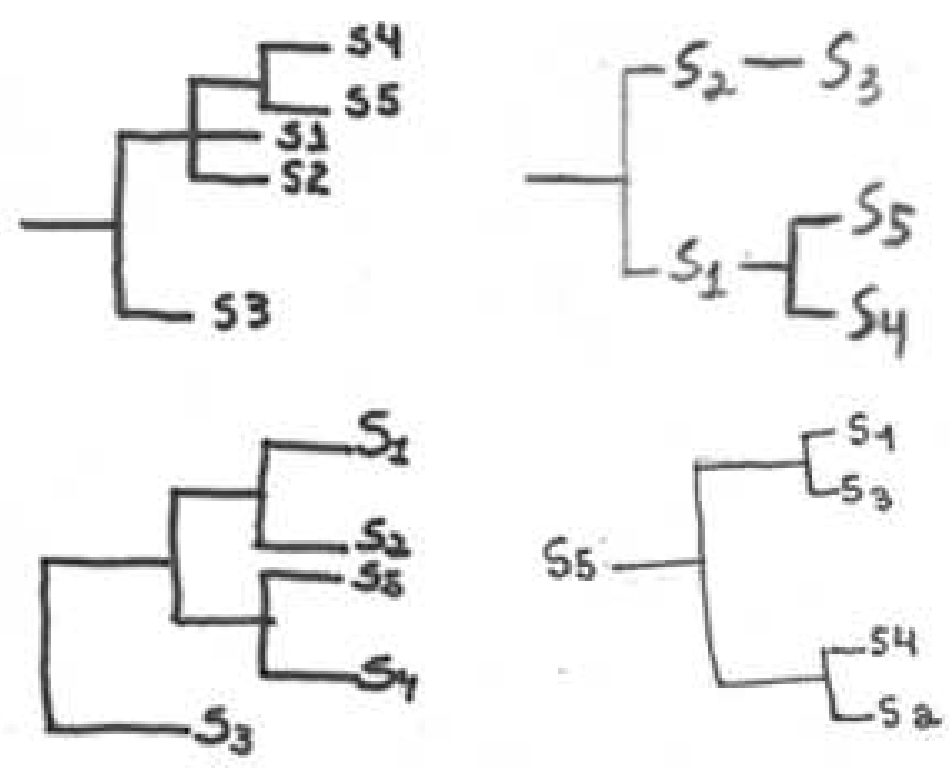

Figura 1 - Representações Esquemáticas das Filogenias Moleculares manuais Executadas pelos alunos participantes do curso.

$\mathrm{Na}$ continuação das atividades práticas, foi apresentada o segundo exercício intitulado "Construindo uma Filogenia Molecular in Silico", executado no Laboratório de Informática da Secretaria de Educação a Distância (SeaD) na Universidade Estadual do Ceará. Na aplicação desta atividade foi apresentado aos alunos o site do banco de dados do NCBI e suas características básicas, tendo como foco a ferramenta BLASTp.

Para a realização da atividade, os alunos, em computadores individuais, acessaram o site do NCBI e, posteriormente a ferramenta BLAST. Em seguida acessaram o link da ferramenta Blastp e realizaram a busca (Search) da sequência de aminoácidos seguinte: mvlsaddktn ikncwgkigg hggeygeeal qrmfaafptt ktyfshidvs. Esta sequência corresponde à proteína hemoglobina de rato, identificada como: NP_037228.1 hemoglobin subunit alpha-1/2 [Rattus norvegicus] >sp|P01946.3|HB - segundo Dale (2005) com acesso efetuado ao NCBI em 10/03/2010. A proteína hemoglobina corresponde a uma das mais bem conhecidas, estudadas e citadas na disciplina de Biologia Molecular.

Após a busca, os alunos analisaram os resultados obtidos dos alinhamentos das sequências através da ferramenta de busca em banco de dados BLAST e, posteriormente, construíram, a partir da ferramenta "Distance Tree of Results", a filogenia molecular desta sequência (Figura 02). 
Tree Method: Fast Minimum Evolution Tree view is RID: 7 CR68SUS01N

Query ID: ICI | 39893

Database used: NR

Max Seq Distance Difference $=0.85$
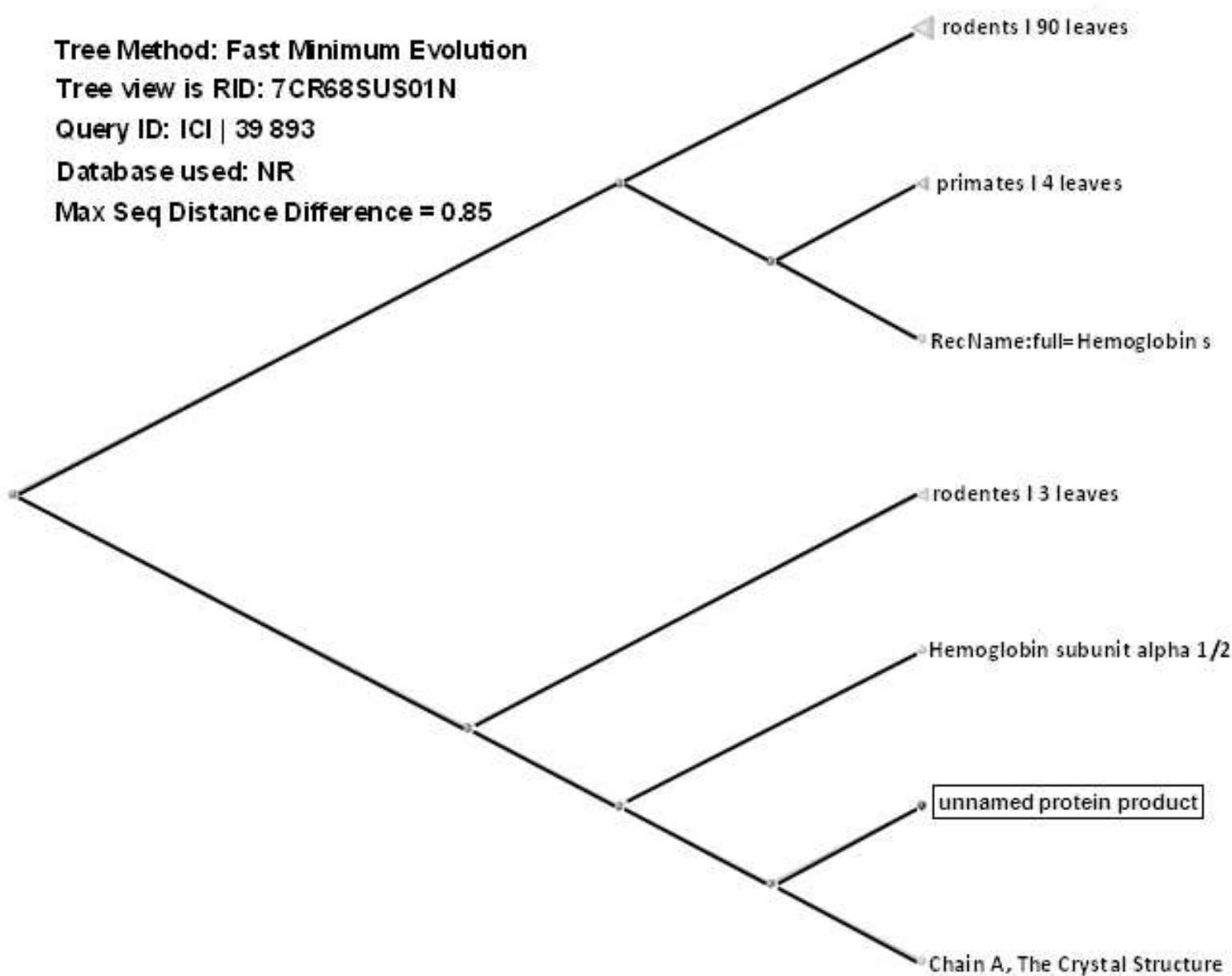

Figura 2 - Representação Obtida da Análise Filogenética por Alinhamento de Sequências pela Ferramenta BLASTp por aluno participante do curso.

Esta figura corresponde à filogenia obtida pelos alunos e analisada em classe, mostrando dois clados: um clado para primatas e roedores e outro para outras sequências não específicas. Percebe-se que no link para roedores existem 97 OTUs (operational taxonomic units), ou seja, as unidades taxonômicas que se deseja comparar, para o grupo dos roedores, a qual foi aberta, apresentando os OTUS.

Na Figura 03 verifica-se na parte superior o número do trabalho: Tree view for RID: 7CR68SUS01N, a identificação da busca: Query ID: IC//39893 e a base de dados utilizada: NR - Não redundante. Outras informações importantes foram observadas, tais como: Fast Minimum Evolution, Max Seq Difference $=0,85$ e a Distância Grishin (protein). Por fim, vê-se que a sequência plotada no banco de dados (destacada no quadro) encontra-se próxima, evolutivamente, da proteína Chain A, The Crystal Structure.

A metodologia apresentada (Fast Minimum Evolution) corresponde à mais simples, também chamada de UPGMA (Unweighted pair group method with arithmetic mean). Este método foi desenvolvido para a construção de fenogramas que apresentem as similaridades fenotípicas entre 
OTUs, mas pode também ser utilizado para construir árvores filogenéticas se as taxas de evolução são aproximadamente constantes entre diferentes linhagens (relação mais ou menos linear entre a distância evolutiva e o tempo de divergência). Para uma correlação segura, a medida dessa distância linear deve estar relacionada ao número de substituições de nucleotídeos ou de aminoácidos por intervalo de tempo.

O método UPGMA utiliza um algoritmo de organizações sequenciais, nos quais as relações topológicas são identificadas por ordem de similaridade e a árvore filogenética é construída passo a passo. Ou seja, primeiro deve-se identificar dentro de várias OTUs, as duas que são mais similares e tratá-las como uma única, chamada de OTU composta. A partir daí são observados os outros grupos de OTUs e é identificado o próximo par com maior similaridade, que é novamente arranjado e assim por diante, até que sobrem apenas duas OTUs (Graur, 1999).

Os estudantes participantes também tiveram oportunidade de alterar as configurações filogenéticas pelos links disponíveis na página, produzindo, por exemplo, árvores por outros métodos; colapsando e estendendo subclados, localizando sequências específicas apresentadas nos links (em vermelho), etc. Comparando-se a atividade manual e in silico, percebe-se que, em sílico foi capaz de apresentar mais informações.

Foi possível perceber que as análises filogenéticas manuais e in silico apresentadas mostram que os alunos captaram e realizaram com êxito as atividades propostas. Deve se notar é claro, que uma árvore filogenética montada através de qualquer um desses métodos não representa a verdade absoluta. Para que obtivéssemos uma árvore perfeita, deveríamos levar em conta uma enorme quantidade de dados, o que, na maioria das vezes, é impossível. O resultado obtido é apenas o melhor possível a partir dos dados de entrada.

Ao fim das atividades práticas, com o intuito de saber qual a percepção do aluno sobre os resultados destas atividades, foi solicitado que descrevessem em no máximo 3 linhas os principais comentários a cerca dos principais pontos obtidos com a aplicação da aula teórica-prática de Introdução à Bioinformática. Assim, foram obtidos os seguintes comentários:

Aluno do Curso de Ciências Biológicas - UECE: "A aplicação foi relevante de forma a mostrar a importância das aplicações em Bioinformática. A única dificuldade foi na formação da filogenia molecular."

Aluno do Curso de Biomedicina - FATECI: "O conceito de Bioinformática foi bastante claro proporcionando aos alunos sua aplicação prática na pesquisa científica." (Aluno do Curso de Biomedicina - FATECI)

Aluno do Curso de Ciências Biológicas - UECE: “Através da aula teórica-prática foi possível conhecer um novo ramo da biologia, até então desconhecido por muitos colegas da turma." 
Aluno do Curso de Ciências Biológicas - UECE: "O método de resolução da atividade é de fácil compreensão e assimilação, porém exige tempo se for feita manualmente sem o auxílio dos computadores que possam medir os scores e organizá-los em grupos próximos."

Os resultados positivos obtidos com a aplicação das atividades práticas foram destacados com as falas dos alunos anteriormente citadas, sendo valorizados por tornar as aulas mais atrativas e por facilitar à compreensão do conhecimento específico, no caso em foco a abordagem do genoma através de ferramentas de Bioinformática. Obviamente não se buscou aqui, uma "escolha" entre as duas metodologias, mas sim, que os alunos pudessem vivenciar o passo a passo necessário para a construção da filogenia molecular e uma visão inicial dos bancos de dados e de seu potencial, para o entendimento da disciplina.

\section{Considerações Finais}

Este estudo proporcionou a construção de um conhecimento didático pedagógico do conteúdo, com definição referida segundo (Schulman,1986), "como um fato que articulou o conhecimento do conteúdo específico de Bioinformática com o conhecimento pedagógico geral da Biologia Molecular e cresce adequando à sua realidade e condições de trabalho com as estratégias de ensino do conteúdo contextualizado".

É preciso deixar claro aos alunos que não devemos abandonar os métodos tradicionais de classificação dos organismos, como a morfologia, fisiologia e paleontologia. Ao invés disso, devemos prover dados complementares e mais precisos sobre as semelhanças e divergências de caracteres. A taxonomia baseada na morfologia e em dados anatômicos é ainda muito importante para a comparação com as informações paleontológicas disponíveis, já que o DNA de formas fósseis é quase impossível de ser recuperado.

Outro ponto negativo onde esbarra a prática da Bioinformática é a barreira da língua, já que estes portais de dados encontram-se na língua inglesa. O próprio linguajar científico e tecnicista. A estrutura dos portais, com centenas de links. Enfim, são barreiras que, no entanto podem se configurar como desafios e contrapontos que poderiam ser encarados, buscando uma nova perspectiva didática. Trata-se então, portanto, de uma iniciativa prática inicial para aproveitar o imenso potencial da Bioinformática no estudo da linguagem da informação genética.

Em fim, compreende-se que estes resultados mostraram o caráter essencial da inserção de conceitos básicos dos novos e emergentes campos das ciências, em especial, o conhecimento do genoma diretamente dos portais de dados, introduzindo a Bioinformática no "currículo de conhecimento" dos alunos participantes da IX Semana da Biologia na Universidade Estadual do Ceará. 


\section{Referências}

Brasil. Ministério da Educação, Secretaria de Educação Média e Tecnológica. Parâmetros

Curriculares Nacionais: Ensino Médio. Brasília: Ministério da Educação. 1999.

Camargo, S. S.; Infante-Malachias M. E.; Amabis, J. M. O Ensino de Biologia Molecular em

Faculdades e Escolas Médias de São Paulo. Revista Brasileira de Ensino de Bioquímica e Biologia Molecular, v.01, artigo A. 2007.

Dale, C. S.; Pagano R. de, L. e Rioli, V. Hemopressin: a novel bioactive peptide derived from the alpha1-chain of hemoglobin. Mem. Inst. Oswaldo Cruz 100 SUPPL 1, 105-106, 2005.

Graur, D.; Li, W.H. Fundamentals of Molecular Evolution. Second Edition, Sinauer Associates, 1999.

Lehninger. Principles of Biochemistry. Eds: Nelson D.L. \& Cox, M.M., 3a edição, Worth Publishers. 2000.

Meneghello, G. E.; Zimmer, P. D.; Malone, G.; Müller, M. M.; Cruz, H. L. Utilização da Bioinformática para Análise Filogenética de A E B Amilases Presentes em Sementes e Outros Tecidos Vegetais. PPGCTS - DFt - FAEM/UFPel Campus Universitário. 2004.

Perezleo, S.L; Arencibia, J. R.; Conill, G. C.; Achón, V. G.; Araújo, R. J. A. Impacto de la Bioinformática en las ciencias biomédicas. Acimed. 2003.

Ricardo, E. C. Implementação dos PCN em sala de aula: dificuldades e possibilidades. Física na Escola, São Paulo, v. 4, n. 1. 2003.

Schulman, L. S. Those Who Understand: knowledge growth in teaching. In Educational Researcher, v.17, n.1, p.4-14. 1986. 
Howard Lopes Ribeiro Junior. Universidade Federal do Ceará. Aluno de Mestrado Acadêmico em Ciências Médicas, Universidade Federal do Ceará. howard.Irj@gmail.com

Roberta Taiane Germano de Oliveira. Universidade Estadual do Ceará. Aluna do curso de Ciências Biológicas e Iniciação Científica do Laboratório de Bioquímica e Cultura de Células, Instituto Superior de Ciências Biomédicas. tayaneoliveira.g@gmail.com

Alex Soares Marreiros Ferraz. Universidade Federal do Piauí (UFP), Universidade Estadual do Ceará (UEC). Professor do Departamento de Educação Física, Universidade Federal do Piauí e Pesquisador do Laboratório de Bioquímica e Cultura de Células, Instituto Superior de Ciências Biomédicas, Universidade Estadual do Ceará. Doutor em Biotecnologia em Saúde (RENORBIO). ferrazalex@hotmail.com

Francisco Fleury Uchoa Santos Júnior. Sociedade Nacional de Fisioterapia Esportiva - Ceará. Doutorando em Biotecnologia em Saúde (RENORBIO), Laboratório de Bioquímica e Cultura de Células, Instituto Superior de Ciências Biomédicas, Universidade Estadual do Ceará. Mestre em Ciências Fisiológicas pela Universidade Estadual do Ceará. fleuryfisiofic@yahoo.com.br

Patrick Simão Carlos. Mestrando Acadêmico em Ciências Fisiológicas, Laboratório de Bioquímica e Cultura de Células, Instituto Superior de Ciências Biomédicas, Universidade Estadual do Ceará. patricksimao@yahoo.com.br

André Accioly Nogueira Machado. Doutorando DINTER/MINTER em Fisiologia (UFRJ/UFMG/UECE), Laboratório de Bioquímica e Cultura de Células, Instituto Superior de Ciências Biomédicas, Universidade Estadual do Ceará. Mestre em Ciências Fisiológicas pela Universidade Estadual do Ceará acciolyandre@gmail.com

Igor Cabral Coutinho do Rêgo Monteiro. Aluno de Mestrado Acadêmico em Ciências Fisiológicas, Laboratório de Bioquímica e Cultura de Células, Instituto Superior de Ciências Biomédicas, Universidade Estadual do Ceará. igorccdrm@hotmail.com

Vânia Marilande Ceccatto. Universidade Estadual do Ceará (UEC). Professora Adjunta Curso de Ciências Biológicas e Laboratório de Bioquímica e Cultura de Células, Instituto Superior de Ciências Biomédicas, Universidade Estadual do Ceará. Doutorado em Bioquímica pela Universidade Federal do Ceará vceccatto@yahoo.com.br 